\title{
Creation of Triple Hierarchical Micro-Meso-Macroporous N-doped Carbon Shells with Hollow Cores Toward the Electrocatalytic Oxygen Reduction Reaction
}

\author{
Ruohao Xing ${ }^{1,2} \cdot$ Tingsheng Zhou ${ }^{2} \cdot$ Yao Zhou $^{2} \cdot$ Ruguang Ma $^{2} \cdot$ Qian Liu $^{2,3} \cdot$ Jun Luo ${ }^{1,3} \cdot$ Jiacheng Wang $^{2,3}$
}

Received: 19 August 2017/ Accepted: 3 September 2017/Published online: 27 September 2017

(C) The Author(s) 2017. This article is an open access publication

\section{Highlights}

- A series of triple hierarchical micro-meso-macroporous $\mathrm{N}$-doped carbon shells have been successfully prepared via etching $\mathrm{N}$-doped hollow carbon spheres with $\mathrm{CO}_{2}$ at high temperatures.

- The activated sample has the large surface area and pore volume, hierarchical micro-mesopore distributions, hollow macropore cores and controllable nitrogen contents.

- The optimized sample shows the comparable oxygen reduction reaction activity but superior methanol tolerance and long-term durability to commercial $\mathrm{Pt} / \mathrm{C}$ with a $4 \mathrm{e}^{-}$-dominant transfer pathway in alkaline media.

\begin{abstract}
A series of triple hierarchical micro-mesomacroporous $\mathrm{N}$-doped carbon shells with hollow cores have been successfully prepared via etching N-doped hollow carbon spheres with $\mathrm{CO}_{2}$ at high temperatures. The surface areas, total pore volumes and micropore
\end{abstract}

Electronic supplementary material The online version of this article (doi:10.1007/s40820-017-0157-1) contains supplementary material, which is available to authorized users.

Qian Liu

qianliu@mail.sic.ac.cn

$\triangle$ Jiacheng Wang

jiacheng.wang@mail.sic.ac.cn

1 School of Materials Science and Engineering, Shanghai University, 99 Shangda Road, Shanghai 200444, People's Republic of China

2 State Key Laboratory of High Performance Ceramics and Superfine Microstructure, Shanghai Institute of Ceramics, Chinese Academy of Sciences, 1295 Dingxi Road, Shanghai 200050, People's Republic of China

3 Shanghai Institute of Materials Genome, Shanghai, People's Republic of China percentages of the $\mathrm{CO}_{2}$-activated samples evidently increase with increasing activation temperature from 800 to $950{ }^{\circ} \mathrm{C}$, while the $\mathrm{N}$ contents show a contrary trend from 7.6 to 3.8 at\%. The pyridinic and graphitic nitrogen groups are dominant among various $\mathrm{N}$-containing groups in the samples. The $950{ }^{\circ} \mathrm{C}$-activated sample (CANHCS-950) has the largest surface area $\left(2072 \mathrm{~m}^{2} \mathrm{~g}^{-1}\right)$, pore volume $\left(1.96 \mathrm{~cm}^{3} \mathrm{~g}^{-1}\right)$, hierarchical micro-mesopore distributions $(1.2,2.6$ and $6.2 \mathrm{~nm})$, hollow macropore cores $(\sim 91 \mathrm{~nm})$ and highest relative content of pyridinic and graphitic $\mathrm{N}$ groups. This triple micro-meso-macropore system could synergistically enhance the activity because macropores could store up the reactant, mesopores could reduce the transport resistance of the reactants to the active sites, and micropores could be in favor of the accumulation of ions. Therefore, the CANHCS-950 with optimized structure shows the optimal and comparable oxygen reduction reaction (ORR) activity but superior methanol tolerance and long-term durability to commercial $\mathrm{Pt} / \mathrm{C}$ with a $4 \mathrm{e}^{-}$dominant transfer pathway in alkaline media. These excellent properties in combination with good stability and recyclability make CANHCSs among the most promising metal-free ORR electrocatalysts reported so far in practical applications. 


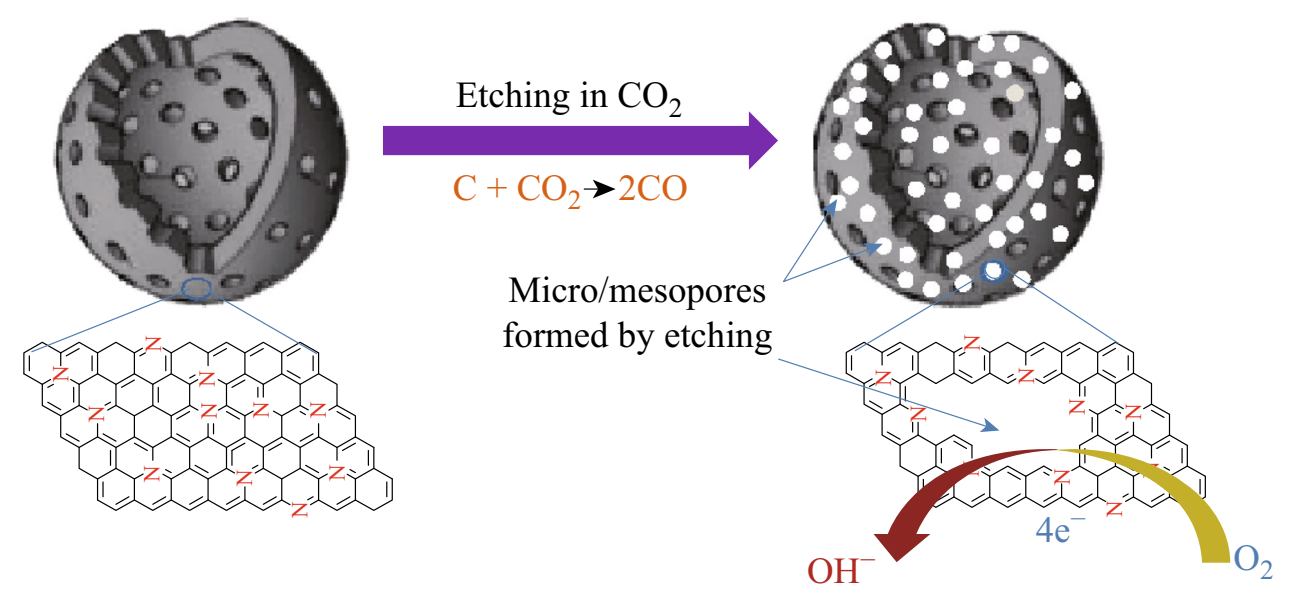

Keywords Hierarchical pores $\cdot$ Hollow cores $\cdot \mathrm{N}$ doping $\cdot$ Electrocatalysis $\cdot$ Oxygen reduction reaction

\section{Introduction}

Fuel cells, which serve as a highly efficient, environmentfriendly energy transformation system, have received intensive research and focus in transports, aerospace and communication equipment during these years [1-3]. However, the wide applications of fuel cells remain a great challenge because of the slower rate of the cathodic oxygen reduction reaction (ORR) [4, 5]. For the ORR process, it encounters difficulties in absorbing $\mathrm{O}_{2}$ and breaking $\mathrm{O}-\mathrm{O}$ double bonds in the cathode. Thus, an infinite energy barrier of the ORR has become one of the most important factors limiting the performance of fuel cells [3, 6-8]. So far, Pt-based materials have been regarded as one of the most active catalysts for the ORR and they can be commercially available at present [9-12]. Pt-based catalysts are highly effective, but they are subjected to some drawbacks including high cost, limited resources and the crossover to methanol. Thus, the large-scale production and commercialization of these Pt-based catalysts in fuel cells are severely limited [13, 14]. So, there is therefore an urgent need, but it is still a significant challenge to reduce the cost and enhance the stability for the ORR catalyst via the design and preparation of non-precious metal ORR electrocatalysts.

A series of nanostructured carbon-based nanostructured materials, such as carbon nanotubes (CNTs) [15, 16], carbon spheres [17, 18], mesoporous carbon [19, 20] and carbon quantum dots [21], have been explored in varied applications including supercapacitors [22-24], gas adsorption [25, 26], removal of heavy metal ions [27], biomedical imaging [28], in virtue of their high stability, low cost and easy availability. The doped heteroatoms (e.g., boron, nitrogen, phosphorus, sulfur and fluorine) with distinct electronegativity with respect to carbon atoms cause the electron modulation to change the charge distribution, electronic properties and chemical activities of the doped carbons [29-31]. Doping carbon materials with nitrogen, which has a similar atomic size to carbon but different electron configuration, is highly effective to improve the ORR activity by adjusting the electronic structures and electron distribution [32]. There are some excellent reviews in the literature dealing with the $\mathrm{N}$-doped carbon materials [33-36]. Recently, various N-doped carbon nanomaterials, including graphene sheets [13, 37-40], CNTs [41-45], carbon nanofibers [12, 46], biomass-derived carbon [47], small molecule precursors [48] and hollow carbon spheres (HCSs) [17, 49-52] have been investigated as the metal-free ORR electrocatalysts due to their unique electronic properties derived from the conjugation between the nitrogen lone-pair electrons and the graphene $\pi$ system $[31,53-56]$. However, there is still a gap between heteroatom-doped carbon materials and commercial $\mathrm{Pt} / \mathrm{C}$. Thus, the continuous searching for highly active metal-free ORR electrocatalysts still remains challenging.

There is no denying that the construction of a nanostructured catalyst with hierarchical porosity and large surface area is beneficial for improving the activity thanking to more accessible active sites [57], fast diffusion of reactants to the active sites and fast release of the products from the sites. The activated porous carbons possess a highly developed porosity with adjustable and hierarchical structure which can be used in a wide range of fields, such as gas- or liquid-phase adsorption processes and electrochemical energy storage [58, 59]. In the field of electrochemical catalysis, the large surface area and porosity 
could improve the catalytic activity by enlarging the limiting current density and lowering the onset potential. $\mathrm{CO}_{2}$ activation is an efficient strategy to increase the porosity and adjust the pore structures of various carbon materials by etching carbon with $\mathrm{CO}_{2}$ at high temperatures. The method of $\mathrm{CO}_{2}$ activation has been applied in various carbon-based materials including resorcinol-formaldehyde resin [60], carbon nanofibers [46] and CMK-1 [61].

In this work, we successfully developed a kind of novel porous $\mathrm{N}$-doped carbons shells with large hollow cores and triple micro-meso-macroporosity $(1.1,2.6,6.2$, $\sim 91 \mathrm{~nm}$ ) by etching $\mathrm{N}$-doped hollow carbon spheres (NHCSs) with $\mathrm{CO}_{2}$ at high temperatures. The $\mathrm{CO}_{2}$ activation treatment allows the formation large amount of micropores and narrow mesopores within the shells, thus significantly improving the surface area and pore volume, although the total $\mathrm{N}$ contents show a downward trend from 7.6 to 3.8 at\% with increasing the activation temperature from 800 to $950{ }^{\circ} \mathrm{C}$. In the activated samples, the pyridinic and graphitic nitrogen groups are dominant among various $\mathrm{N}$-containing groups, which are active for the ORR. Among various samples, the $950{ }^{\circ} \mathrm{C}$-activated sample (CANHCS-950) has the largest surface area $\left(2072 \mathrm{~m}^{2} \mathrm{~g}^{-1}\right)$ and pore volume $\left(1.96 \mathrm{~cm}^{3} \mathrm{~g}^{-1}\right)$ and highest relative content of pyridinic and graphitic $\mathrm{N}$ groups. Due to its unique structures of triple hierarchical micro-meso-macroporosity, large surface area and highcontent doping of pyridinic and graphitic $\mathrm{N}$ groups, CANHCS-950 demonstrates the best ORR activity among these samples, which is comparable to commercial $\mathrm{Pt} / \mathrm{C}$. The macropores of hollow cores $(\sim 91 \mathrm{~nm})$ could store up the electrolyte and close the spread distance between the electrolyte and materials. The mesopores (2.6 and $6.2 \mathrm{~nm}$ ) could reduce the transport resistance of the reactants to the active sites [62-64]. The as-formed micropores could be in favor of the accumulation of ions $(1.1 \mathrm{~nm})$ [65]. Moreover, it could catalyze the ORR via a close four-electron reaction process with very low yield of peroxides as the side product, thus obtaining the maximum energy transformation efficacy. Furthermore, it also shows the superior long-term stability and methanol tolerance to commercial $\mathrm{Pt} / \mathrm{C}$ for $\mathrm{ORR}$, indicating that CANHCS-950 is a good candidate for replacing $\mathrm{Pt} / \mathrm{C}$ used in fuel cells.

\section{Experimental Section}

\subsection{Chemicals}

Hexamethylentetramine (HMT), 2,4-dihydroxybenzoic acid (DA), sodium oleate $(\mathrm{SO})$, potassium hydroxide $(\mathrm{KOH})$, anhydrous ethanol (EtOH), carbon dioxide $\left(\mathrm{CO}_{2}\right)$ and ammonia $\left(\mathrm{NH}_{3}\right)$ were purchased from Sinopharm Chemical Reagent Co. Ltd. $\mathrm{CH}_{3} \mathrm{OH}$ was purchased Shanghai Lingfeng Chemical Reagent Co. Ltd. The PEO-PPO-PEO triblock copolymers $\mathrm{P} 123\left(\mathrm{EO}_{20} \mathrm{PO}_{70} \mathrm{EO}_{20}, M_{v}=5800\right)$ and Nafion solution $(5 \mathrm{wt} \%)$ were purchased from Aldrich. The commercial Pt/C catalyst (20 wt \%) was obtained from Johnson Matthey (UK). All solvents and chemicals were utilized as received without any further purification.

\subsection{Materials Synthesis}

\subsubsection{Preparation of Hollow Polymer Spheres (HPSs)}

The HPSs were prepared via the hydrothermal polymerization as reported by the previous study [26]. Double surfactants P123 and SO were used as the soft templates while DA and HMT acted as the carbon sources. Typically, DA $(2.4 \mathrm{mmol})$ and HMT $(2 \mathrm{mmol})$ were mixed in $120 \mathrm{~mL}$ of deionized water under vigorous stirring for at least $10 \mathrm{~min}$ until forming a homogeneous solution A. SO $(0.48 \mathrm{mmol})$ and P123 $(0.015 \mathrm{mmol})$ were then added into $40 \mathrm{~mL}$ deionized water under stirring for about $60 \mathrm{~min}$ to obtain homogeneous solution $\mathbf{B}$. Then, solution $\mathbf{B}$ was dropped into A slowly under vigorous stirring. The color of the solution changed gradually from hyaline to milk white. After stirring for $10 \mathrm{~min}$, the mixed solution was transferred into a Teflonlined stainless steel autoclave with $200 \mathrm{~mL}$ and heated at $160{ }^{\circ} \mathrm{C}$ for $8 \mathrm{~h}$. After cooling to room temperature, the resulting precipitates (HPSs) were collected by centrifugation and dried at $80{ }^{\circ} \mathrm{C}$ under vacuum overnight after washing with deionized water for three times.

\subsubsection{Preparation of $\mathrm{N}$-doped Hollow Carbon Spheres (NHCSs)}

The HPSs were thermally treated at $650{ }^{\circ} \mathrm{C}$ for $3 \mathrm{~h}$ with a heating rate of $2{ }^{\circ} \mathrm{C} \mathrm{min}^{-1}$ in $\mathrm{NH}_{3}$ atmosphere at a gas flow rate of $40 \mathrm{~mL} \mathrm{~min}^{-1}$ to obtain NHCSs.

\subsubsection{Activation of NHCSs by $\mathrm{CO}_{2}$ at High Temperature}

The $\mathrm{CO}_{2}$-activated NHCSs (CANHCSs) were prepared by reacting NHCSs with $\mathrm{CO}_{2}$ in a tubular furnace at controlled temperatures $\left(800,900,950{ }^{\circ} \mathrm{C}\right)$ for $30 \mathrm{~min}$ with a heating rate of $10{ }^{\circ} \mathrm{C} \mathrm{min}^{-1}$. The final products were named as CANHCS-800, CANHCS-900 and CANHCS-950, respectively, depending on the activation temperature.

\subsection{Structural Characterization}

Scanning electron microscopy (SEM) was carried out using a field emission scanning electron micro-analyzer (FEI 
Magellan 400), and transmission electron microscopy (TEM) images were taken by JEM-2100F. Raman spectra were collected on a DXR Raman Microscope (Thermal Scientific Co., USA) with $532 \mathrm{~nm}$ excitation length. Nitrogen adsorption-desorption isotherms were measured at liquid nitrogen temperature (77 K) with an ASAP 2010 Accelerated Surface Area and Pore Size Analyzer System (Micrometitics, Norcross, GA). During measuring procedures, the samples were treated at $300{ }^{\circ} \mathrm{C}$ overnight under vacuum. The specific surface areas were calculated with the Brunauer-Emmett-Teller (BET) method. The total pore volume was calculated from the amount of nitrogen adsorbed at a relative pressure of 0.99 . The pore size distribution curves were calculated by means of the desorption branch of the isotherms using the quenched solid density functional theory (QSDFT). X-ray photoelectron spectroscopy (XPS) measurements were taken using an ESCALAB $250 \mathrm{X}$-ray photoelectron spectrometer using Al $K \alpha(h v=1486.6 \mathrm{eV})$ radiation to analyze the surface of the obtained samples.

\subsection{Electrode Preparation and Electrochemical Measurements}

The catalyst inks were prepared by mixing $5 \mathrm{mg}$ catalyst with $30 \mu \mathrm{L}$ of Nafion solution ( $5 \mathrm{wt} \%$ ), $500 \mu \mathrm{L}$ deionized water and $500 \mu \mathrm{L}$ ethanol under ultrasonic irradiation for $2 \mathrm{~h}$ until a uniform mixture was obtained. Then, $20 \mu \mathrm{L}$ of the ink was dropped on the working electrode by a microinjector and it was dried at $50{ }^{\circ} \mathrm{C}$ for $10 \mathrm{~min}$ until the sample formed a film. The Pt/C catalyst $(20 \mathrm{wt} \% \mathrm{Pt}$ on carbon, Sigma-Aldrich) ink was also used for preparing the working electrode in the same way.

The electrochemical measurements were tested in $0.1 \mathrm{M}$ $\mathrm{KOH}$ solution using a three-electrode system with an electrochemical workstation (Pine Instrument Co.). A saturated calomel electrode (SCE) and a Pt plate were used as the reference electrode and the counter electrode, respectively. A rotating disk electrode (RDE) was used the working electrode for cyclic voltammetry (CV) or linear sweep voltammetry (LSV) measurements, and a rotating ring-disk electrode (RRDE) was used the working electrode for dual-electrode CV (DECV) measurements. The electrolyte was saturated by using high-purity bubbling $\mathrm{N}_{2}$ or $\mathrm{O}_{2}$ for $0.5 \mathrm{~h}$ before the test, and all the experiments were carried in $25^{\circ} \mathrm{C}$.

In the case of the RDE tests, cyclic voltammetry (CV) measurement was performed from -1 to $0.2 \mathrm{~V}$ (vs. SCE) in $\mathrm{O}_{2}$-saturated in $0.1 \mathrm{M} \mathrm{KOH}$ solution with a sweep rate of $50 \mathrm{mV} \mathrm{s}^{-1}$ for 50 times' cycle for activating electrode and $10 \mathrm{mV} \mathrm{s}^{-1}$ for 3 times' cycle for data recording. Linear sweep voltammetry (LSV) measurements were conducted from 0 to $-1.0 \mathrm{~V}$ (vs. SCE) in $\mathrm{O}_{2}$-saturated with a sweep rate of $10 \mathrm{mV} \mathrm{s}^{-1}$ at different rotating speeds of 400, 625, 900, 1225, 1600, and $2025 \mathrm{rpm}$.

For the RRDE tests, a CG disk $\left(0.2475 \mathrm{~cm}^{2}\right)$ was used as a working electrode which was surrounded by a Pt ring $\left(0.1866 \mathrm{~cm}^{2}\right.$ ). The ring potential was held at $0.2 \mathrm{~V}$ (vs. SCE) with a rotating speed of $1600 \mathrm{rpm}$ while the scanning rate was $10 \mathrm{mV} \mathrm{s}^{-1}$. The ring current and disk current were collected in $\mathrm{O}_{2}$-saturated $0.1 \mathrm{M} \mathrm{KOH}$ from GC disk and $\mathrm{Pt}$ ring, respectively. The apparent number of electrons transferred $(n)$ and the percentage of $\mathrm{H}_{2} \mathrm{O}_{2}$ released $\left(\% \mathrm{H}_{2} \mathrm{O}_{2}\right)$ during the ORR process are calculated as follows:

$n=4 \frac{I_{\mathrm{d}}}{I_{\mathrm{d}}+I_{\mathrm{r}} / N}$

$\% \mathrm{H}_{2} \mathrm{O}_{2}=200 \frac{I_{\mathrm{r}} / N}{I_{\mathrm{d}}+I_{\mathrm{r}} / N}$

where $I_{\mathrm{d}}$ is the disk current, $I_{\mathrm{r}}$ is the ring current and $N$ (the value is 0.37) is the collection efficiency of the Pt ring electrode.

\section{Results and Discussion}

As presented in Fig. 1, NHCSs with hollow macroporous core were synthesized by pyrolysis of HPSs in flowing $\mathrm{NH}_{3}$. The subsequent reaction with $\mathrm{CO}_{2}$ could generate large amount of additional micro-mesopores within the shells in the $\mathrm{CO}_{2}$-activated NHCSs (CANHCSs). This $\mathrm{CO}_{2}$ activation process could lead to the significant carbon loss via the release of the volatile matter by the reaction with $\mathrm{CO}_{2}$ [60]. The yields of the activated samples at different temperature $\left(800,900\right.$, and $\left.950{ }^{\circ} \mathrm{C}\right)$ could be calculated as follows:

Yield $(\%)=\left[W_{1} / W_{2}\right] \times 100 \%$

where $W_{1}$ is the weight of CANHCSs and $W_{2}$ is the weight of parent NHCSs. As expected, the yield evidently decreases with the increase in the activation temperature, implying that more carbon burns off at higher temperature via the reaction with $\mathrm{CO}_{2}$ (Fig. 2). At $800{ }^{\circ} \mathrm{C}$, the carbon yield is $82.7 \%$ and the $900{ }^{\circ} \mathrm{C}$ activation results in the lower carbon yield $(58.8 \%)$. At $950{ }^{\circ} \mathrm{C}$, only $10.0 \%$ carbon was remained, implying the majority of carbon burned away. These results and trends are well consistent with the previous research [26, 61-66]. The unique hierarchical micro-mesoporous shell of CANHCSs with large macroporous cores is advantageous for improving the catalytic activity because of enhanced mass-transfer kinetics and the accessibility of active sites in mesopores, accumulated electrolyte ions in micropores and large storage capacity of the electrolyte in macroporous cores [67]. 


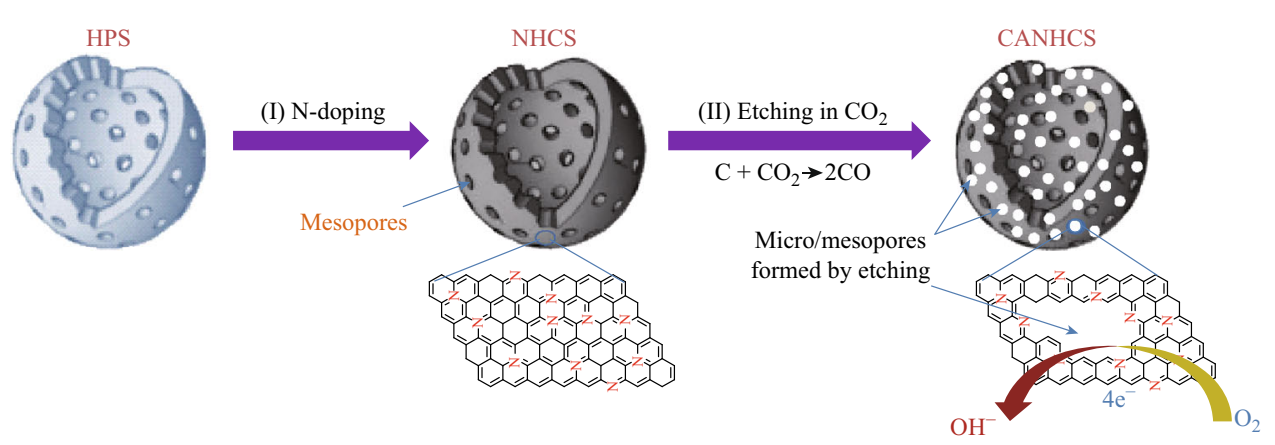

Fig. 1 Scheme for the synthesis of CANHCS with hollow macroporous core and hierarchical micro-mesopores as highly active metal-free

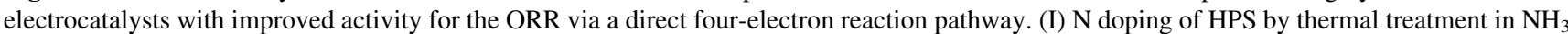
and (II) etching NHCS via the reaction with $\mathrm{CO}_{2}$ at high temperature to form micro-mesopores within the shells

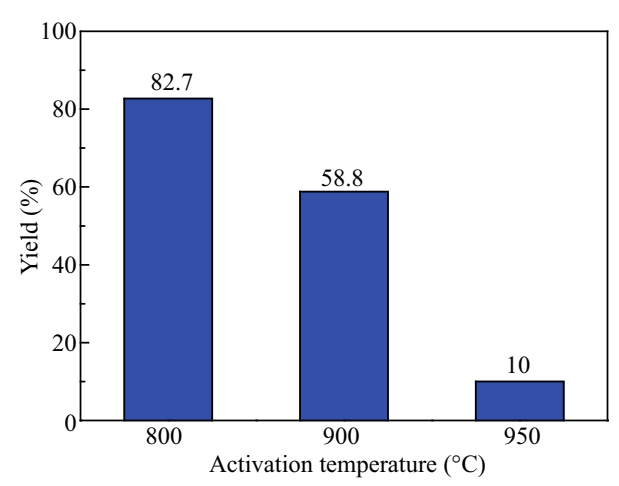

Fig. 2 Yield of the activated samples prepared by the activation of NHCSs with $\mathrm{CO}_{2}$ at different temperatures. Yield $(\%)=$ the ratio of the mass of the activated product divided by the mass of the original weight of NHCSs $\times 100 \%$

The effects of $\mathrm{CO}_{2}$ activation on the morphologies of carbon spheres were studied by SEM and TEM. As shown in Fig. 3, the as-prepared HPSs consist of well-dispersed spherical particles (Fig. 3a), and their morphology is still well retained after treatment in $\mathrm{NH}_{3}$ flow (Fig. 3b). Subjected to the $\mathrm{CO}_{2}$ activation treatment, CANHCSs still maintain excellent spherical morphology, but their surfaces evidently become rougher and rougher with increasing the temperature (Fig. 3c-e), implying the activation process has a great effect on the surface of spheres. Specifically, in spite of $90 \%$ carbon loss at $950{ }^{\circ} \mathrm{C}$, the resulting CANHCS-950 still maintains the parent morphology of NHCSs. However, the activation treatment under $\mathrm{CO}_{2}$ atmosphere leads to the evident decrease in the size of the particles, as evidenced by size distributions (Fig. S1). The original NHCSs have the diameters of 100-165 nm and an average diameter of $144.4 \mathrm{~nm}$. As shown in Fig. 3f, after the activation with $\mathrm{CO}_{2}$, the sizes of the CANHCSs are evidently smaller than that for NHCSs, and their sizes present the decreasing trend with increasing the activation temperature, well matching with the trend of carbon yields. The CANHCS-800, CANHCS-900 and CANHCS-950 have an average diameter of $135.4,129.1$ and $117.8 \mathrm{~nm}$, respectively, significantly smaller than that for NHCSs, which could be mainly ascribed to the following two issues: (1) the carbon framework exposed to the higher temperatures generally resulted in the contraction of the lattice and reduction in the pore sizes and (2) etching off more carbon with $\mathrm{CO}_{2}$ at higher temperature also could cause the decrease in the sizes of carbon spheres.

As shown in Fig. 4a, b, it is clearly observed that NHCSs have a hollow spherical structure with the shell thickness of $\sim 23 \mathrm{~nm}$ and hollow core of $\sim 108 \mathrm{~nm}$. After the activation with $\mathrm{CO}_{2}$ at $950{ }^{\circ} \mathrm{C}$, the sizes of the resulting CANHCS-950 evidently decreased (Fig. 4c), but the spherical morphology is still kept well (Fig. 4d), matching with the SEM observation. The higher-resolution TEM image of a single sphere for CANHCS-950 shows that $\mathrm{CO}_{2}$ activation has a great effect on the microstructure of carbon sphere. It has a smaller thickness of $\sim 14 \mathrm{~nm}$ and hollow core of $\sim 91 \mathrm{~nm}$ than those for NHCSs (Fig. 4d). The activated spheres look like much looser than that in Fig. 4b, and many white fine "dots" are clearly observed, which should be the pores formed by etching off carbon with $\mathrm{CO}_{2}$. More information about pore textures could be obtained from the $\mathrm{N}_{2}$ sorption measurements.

All the pore characteristics of the samples were tested by the $\mathrm{N}_{2}$ adsorption-desorption experiments at $-196{ }^{\circ} \mathrm{C}$. The results of pore structures of the samples are summarized in Table 1. The surface areas were determined by the BET method while the surface area of micropores and mesopores were determined by the t-plot method. The values of total volume and micropore volume were calculated according to the DFT method and HK method, respectively. As shown in Fig. 5a, the $\mathrm{N}_{2}$ adsorption-desorption isotherms of all samples are typical type IV with a H1-type hysteresis loop. There is a sharp capillary condensation step in the relative pressure range from 0.40 to 0.55 . It means that these materials have both mesopores and micropores. NHCSs have a surface area of $846 \mathrm{~m}^{2} \mathrm{~g}^{-1}$ in which the micropore surface $\left(331 \mathrm{~m}^{2} \mathrm{~g}^{-1}\right)$ dominates 

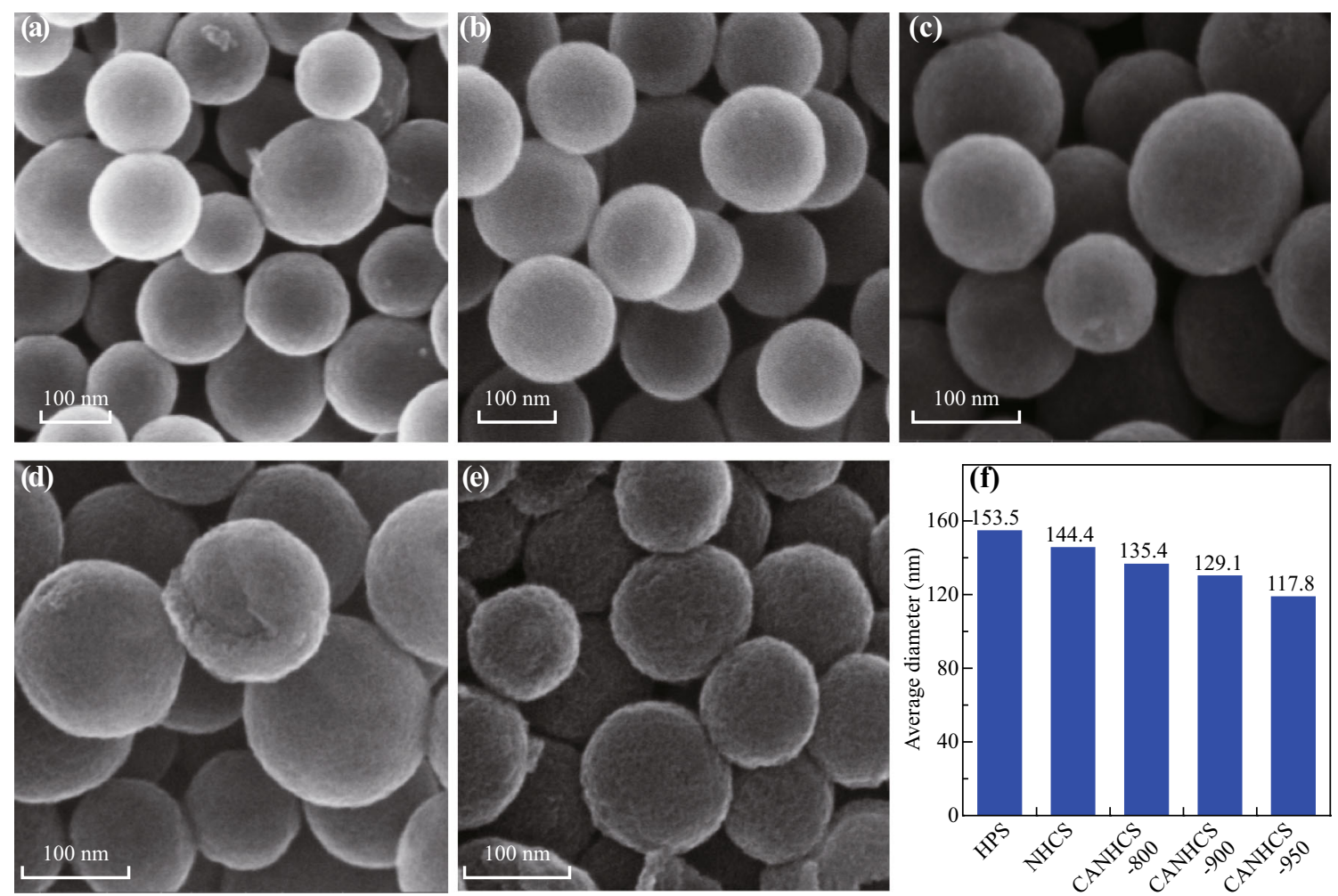

Fig. 3 SEM images of a HPSs, b NHCSs, c CANHCS-800, d CANHCS-900, e CANHCS-950 and $\mathbf{f}$ average diameters of carbon spheres calculated from panel a-e
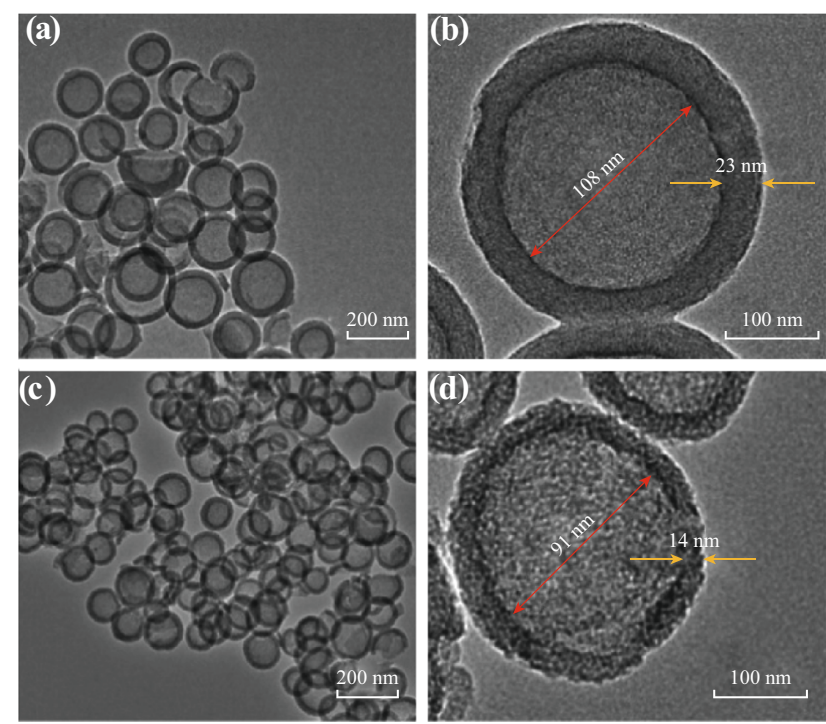

Fig. 4 TEM images of a-b NHCSs and c-d CANHCS-950

$39.13 \%$. The adsorbed amount evidently increases with the increased activation temperature (Fig. 5a), indicating the larger surface areas for the activated samples. Indeed, CANHCS-800, CANHCS-900 and CANHCS-950 have a specific surface area value of 972,1338 , and $2072 \mathrm{~m}^{2} \mathrm{~g}^{-1}$, respectively. This trend is opposite to that for their mass losses (Fig. 2), implying these pores were formed by etching with $\mathrm{CO}_{2}$. It is notable that the percent of micropore areas significantly increases (from $39.13 \%$ for NHCSs to $46.19 \%$ for CANHCS-800, $52.47 \%$ for CANHCS- 800 and $60.33 \%$ for CANHCS-800) with higher activation temperatures and indicates that the $\mathrm{CO}_{2}$ activation is beneficial for micropore formation. Similarly, the micropore volumes and the percent of micropore volumes also increase as the activation temperature increases. Although the percent of mesopore areas and volumes for the activated samples decreased, their actual surface areas and pore volumes evidently increase with the increased activation temperatures (Fig. 5b). Anyway, CANHCS-950 has the largest surface area of $2072 \mathrm{~m}^{2} \mathrm{~g}^{-1}$ and pore volume of $1.96 \mathrm{~cm}^{3} \mathrm{~g}^{-1}$ among these samples. Moreover, the ultralarge surface area and pore volume are expected to show the improved ORR activity since the porous materials with well-defined porosity, high specific surface area and pore volume not only have more accessible active sites, but also promote the efficient transport of the electrolyte, reactants and products [68].

The pore size distributions for NHCSs and CANHCSs are presented in Fig. 5c. The original NHCSs show three maximum values $(1.2,3.2$, and $6.2 \mathrm{~nm})$ of pore sizes (Table 1). Upon activation, the volume adsorbed improves obviously with the increment of the activation temperature (Fig. 5c). However, the higher activation temperature 
Table 1 Texture parameters of NHCSs and CANHCSs activated at different temperatures

\begin{tabular}{|c|c|c|c|c|c|c|c|c|}
\hline \multirow[t]{2}{*}{ Samples } & \multirow[t]{2}{*}{$S_{\mathrm{BFT}}^{\mathrm{a}}\left(\mathrm{m}^{2} \mathrm{~g}^{-1}\right)$} & \multirow[t]{2}{*}{$S_{\text {micro }}^{\mathrm{b}}\left(\mathrm{m}^{3} \mathrm{~g}^{-1}\right)$} & \multirow[t]{2}{*}{$S_{\text {micro }} / S_{\mathrm{BET}}(\%)$} & \multirow[t]{2}{*}{$V_{\text {total }}^{\mathrm{c}}\left(\mathrm{cm}^{3} \mathrm{~g}^{-1}\right)$} & \multirow[t]{2}{*}{$V_{\text {micro }}^{\mathrm{d}}\left(\mathrm{cm}^{3} \mathrm{~g}^{-1}\right)$} & \multirow[t]{2}{*}{$V_{\text {micro }} / V_{\text {total }}(\%)$} & \multicolumn{2}{|c|}{ Pore size $(\mathrm{nm})^{\mathrm{e}}$} \\
\hline & & & & & & & Micro & Meso \\
\hline NHCSs & 846 & 331 & 39.13 & 0.87 & 0.29 & 33.33 & 1.2 & $3.2 / 6.2$ \\
\hline CANHCS-800 & 972 & 448 & 46.09 & 0.86 & 0.32 & 37.21 & 1.1 & $3.2 / 6.2$ \\
\hline CANHCS-900 & 1338 & 702 & 52.47 & 1.16 & 0.48 & 41.38 & 1.2 & $3.3 / 6.2$ \\
\hline CANHCS-950 & 2072 & 1250 & 60.33 & 1.96 & 0.99 & 50.51 & 1.2 & $2.6 / 6.2$ \\
\hline
\end{tabular}

${ }^{\text {a }}$ Surface area determined by the BET method

${ }^{b}$ Micropore surface area determined by the t-plot method

${ }^{\mathrm{c}}$ DFT method cumulative pore volume

${ }^{\mathrm{d}}$ Micropore volume by the HK method

${ }^{\mathrm{e}}$ Maximum values of the pore size distribution determined by the DFT method
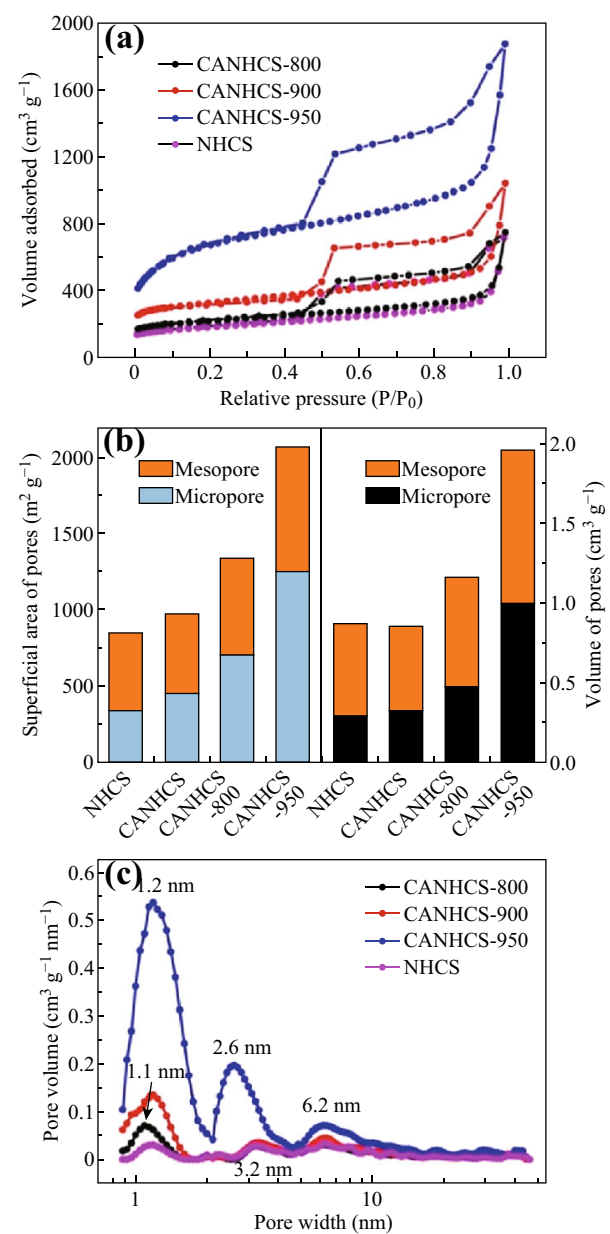

Fig. 5 a $\mathrm{N}_{2}$ adsorption-desorption isotherms, b the superficial areas and pore volumes in the range of micropore and mesopore, $\mathbf{c}$ pore distribution curves of NHCSs, CANHCS-800, CANHCS-900, and CANHCS-950

significantly leads to the widening of pores, although the maximum position value for mesopore size $(2.6 \mathrm{~nm})$ changes smaller. Such a hierarchical micro-mesoporous
$\mathrm{N}$-doped carbon shells with large hollow macroporous cores could contribute to the efficient storage of electrolyte in macroporous cores, fast transport of the electrolyte, reactants and products through mesopores, and effective accumulation of electrolyte ions in micropores, thus improving the electrocatalytic ORR performance.

The effect of $\mathrm{CO}_{2}$ activation on the functional groups of the surfaces' nature could be obtained by XPS. XPS survey spectra and high-resolution N1s spectra for all samples are shown in Fig. 6a-e. In Fig. 6a, there are obvious signals from carbon $(\mathrm{C} 1 \mathrm{~s}, \sim 284.8 \mathrm{eV})$, nitrogen $(\mathrm{N} 1 \mathrm{~s}$, $\sim 398.4 \mathrm{eV}$ ) and oxygen elements $(\mathrm{O} 1 \mathrm{~s}, \sim 532.2 \mathrm{eV})$ for all samples. The summaries of elemental compositions of CANHCSs are listed in Table 2. The presence of the N1s peak in the spectrum of NHCSs indicates that the $\mathrm{N}$ atoms have been successfully doped within the carbon framework by pyrolysis in $\mathrm{NH}_{3}$ (Fig. 6a). For the CANHCSs, the contents of carbon increase gradually while those of nitrogen drop off from 7.6 to 3.8 at\% with the activation temperature rising from 800 to $950{ }^{\circ} \mathrm{C}$. Therefore, the N/C molar ratios for CANHCSs decrease with increasing the activation temperature, suggesting the elimination of $\mathrm{N}$ atoms at higher temperatures. It is known that $\mathrm{CO}_{2}$ can react with carbon materials under high temperature to form plenty of micropores and narrow mesopores, thus resulting in the decrease in the nitrogen contents. The doping of $\mathrm{N}$ atoms into carbon could enhance the electrocatalytic activity because $\mathrm{N}$ doping can modify the electronic structures, chemical activities and Fermi level of the adjacent carbon atoms, favorably adsorbing and activating $\mathrm{O}_{2}$ molecules. However, the total nitrogen content is a less important factor affecting the activity than the nitrogen binding configurations and their relative contents [69]. Thus, the detailed nitrogen bonding configurations were further studied by high-resolution N1s XPS spectra.

As shown in the high-resolution XPS analysis of N1s spectra (Fig. 6b-e), four kinds of nitrogen functional 

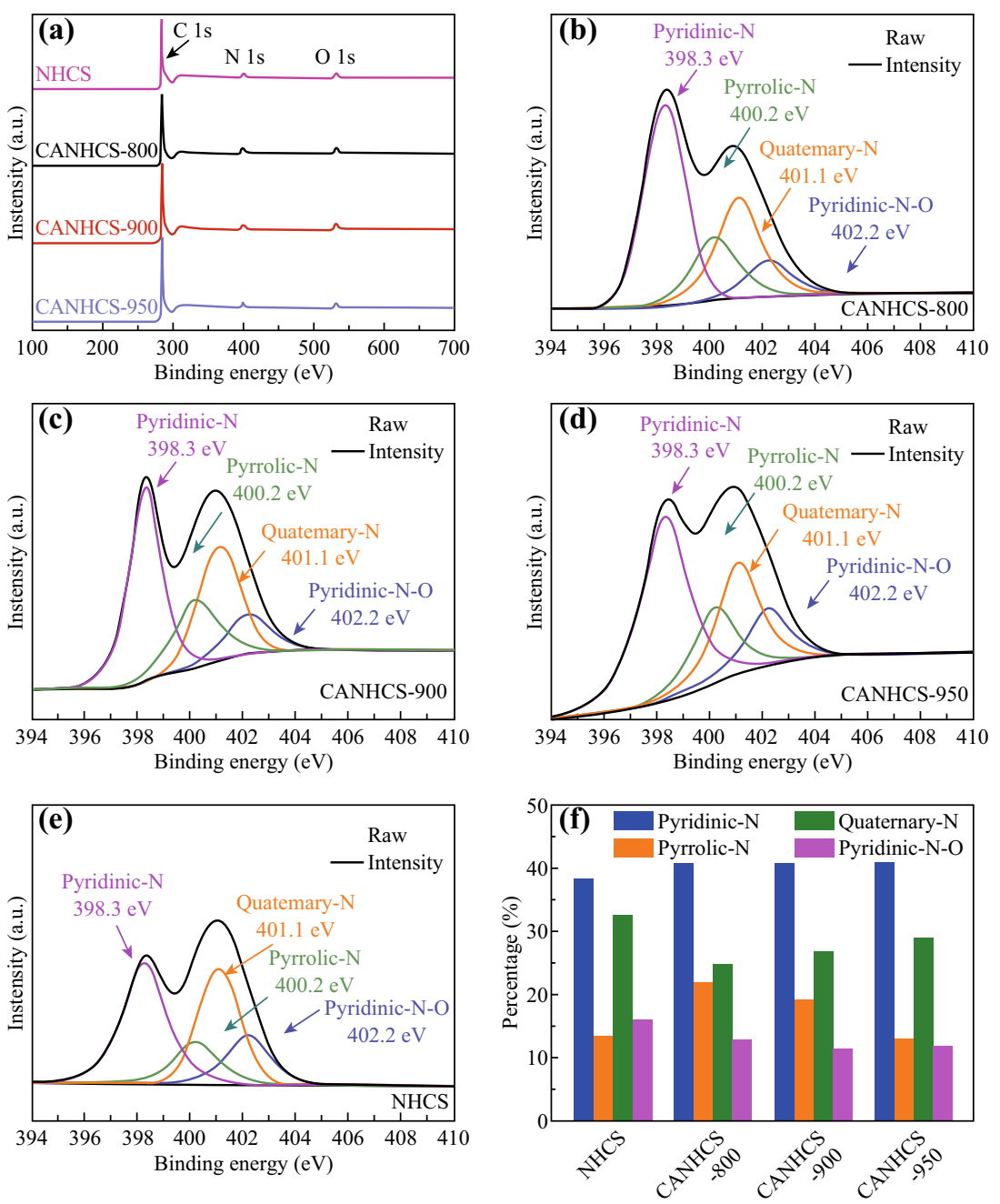

Fig. 6 a XPS spectra of NHCSs, CANHCS-800, CANHCS-900 and CANHCS-950, b-e high-resolution XPS analysis of N 1s for b CANHCS-800, c CANHCS-900, d CANHCS-950 and e NHCSs. $\mathbf{f}$ relative atomic percentage (\%) of different $\mathrm{N}$ functionalities received from the $\mathrm{N} 1 \mathrm{~s}$ peaks

Table 2 Elemental compositions of CANHCSs determined by the XPS analysis

\begin{tabular}{lllll}
\hline Samples & Carbon (at\%) & Nitrogen $($ at $\%)$ & Oxygen $($ at $\%)$ & N/C molar ratio \\
\hline CANHCS-800 & 88.5 & 7.6 & 3.9 & 0.086 \\
CANHCS-900 & 90.0 & 5.5 & 4.5 & 0.061 \\
CANHCS-950 & 91.8 & 3.8 & 4.4 & 0.041 \\
\hline
\end{tabular}

Table 3 Peak positions and relative compositions of different $\mathrm{N}$ functional groups obtained from the highresolution N1s signals

\begin{tabular}{|c|c|c|c|c|c|c|c|c|}
\hline \multirow[t]{2}{*}{ Sample } & \multicolumn{2}{|l|}{ Pyridine N } & \multicolumn{2}{|l|}{ Pyrrolic N } & \multicolumn{2}{|l|}{ Quaternary N } & \multicolumn{2}{|l|}{ Pyridinic $\mathrm{N}-\mathrm{O}$} \\
\hline & Position (eV) & at $\%$ & Position (eV) & at $\%$ & Position (eV) & at $\%$ & Position $(\mathrm{eV})$ & at $\%$ \\
\hline NHCSs & 398.3 & 38.2 & 400.2 & 13.4 & 401.1 & 32.4 & 402.2 & 16.0 \\
\hline CANHCS-800 & 398.3 & 40.9 & 400.2 & 21.7 & 401.1 & 24.7 & 402.2 & 12.7 \\
\hline CANHCS-900 & 398.3 & 42.9 & 400.2 & 19.2 & 401.1 & 26.7 & 402.2 & 11.2 \\
\hline CANHCS-950 & 398.3 & 46.5 & 400.2 & 12.8 & 401.1 & 28.9 & 402.2 & 11.8 \\
\hline
\end{tabular}

groups are doped including pyridinic $\mathrm{N}$, pyrrolic $\mathrm{N}$, quaternary $\mathrm{N}$ and pyridinic $\mathrm{N}-\mathrm{O}$ which center at $\sim 398.3$, $\sim 400.2$, $\sim 401.1$, and $\sim 402.2 \mathrm{eV}$ for binding energy, respectively $[36,50,70]$. The peak positions and relative compositions of different $\mathrm{N}$ groups of trained from the N1s signals are shown in Fig. 6f and Table 3. Obviously, the 


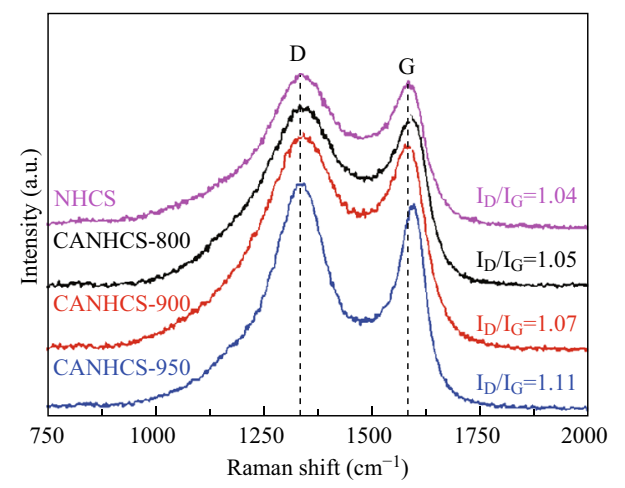

Fig. 7 Raman spectra of NHCSs, CANHCS-800, CANHCS-900 and CANHCS-950

nitrogen species of the samples vary depending on the activation temperature. It has been reported that both pyridinic and graphitic $\mathrm{N}$ groups could promote the electrocatalytic ORR by lowering the overpotential and increasing the current density. Based on the peak areas, it is found that the pyridinic and graphitic groups dominates most of the $\mathrm{N}$ groups in these CANHCSs, and the relative content of pyridinic $\mathrm{N}$ groups is more than 40 at\%. Specifically, CANHCS-950 possesses the largest relative contents of pyridinic and graphitic $\mathrm{N}$ groups. Both pyridinic and graphitic $\mathrm{N}$ groups are considered as the active sites for the ORR, which could lower the overpotential and increase the current density [30, 71, 72]. Considering its highest surface area and unique hierarchical structure with hollow core, it is expected that CANHCS-950 could demonstrate the superior ORR activity.

The structural information and the existence of the graphitic domains on the samples are further obtained by Raman spectroscopy (Fig. 7). The disorder-induced D-band is ranging from 1200 to $1450 \mathrm{~cm}^{-1}$, and the tangential stretch $G$ band is between 1500 and $1600 \mathrm{~cm}^{-1}$ [73]. There is the disordered carbon peak " $\mathrm{D}$ " at $\sim 1330 \mathrm{~cm}^{-1}$ and the graphitic carbon peak " $\mathrm{G}$ " at $\sim 1580 \mathrm{~cm}^{-1}$. Both peaks of CANHCSs become stronger as the activation temperature goes on, and all of them are higher than those for NHCSs. The D peak refers to the structural defects on the graphitic plane and partially disordered structures in carbon materials, whereas the $\mathrm{G}$ peak corresponds to the $E_{2 \mathrm{~g}}$ vibration of graphitic carbon skeleton [74]. The degree of graphitization, defects and edge sites can be found by analyzing the relative intensities of these two lines depend on the type of graphitic materials [75]. The specific value of $D$ peak and $G$ peak can be used to indicate the graphitization degree. The values $I_{\mathrm{D}} / I_{\mathrm{G}}$ ratios increase from 1.04 for NHCSs to 1.05 for CANHCS800, 1.07 for CANHCS-900 and 1.11 for CANHCS-950, indicating more defects and edge sites were created by $\mathrm{CO}_{2}$ activation.
The dimension of graphite crystallite $L_{\mathrm{a}}$ which formed the amorphous carbon can be figured out by Eq. 4 and was inversely proportional to $I_{\mathrm{D}} / I_{\mathrm{G}}$ [76]. The relationship of the parameters is as follows:

$\frac{I_{\mathrm{D}}}{I_{\mathrm{G}}}=\frac{C\left(\lambda_{\mathrm{L}}\right)}{L_{\mathrm{a}}}$

Therein, $\lambda_{\mathrm{L}}$ is the wavelength of incident light and the $C\left(\lambda_{\mathrm{L}}\right)$ is a coefficient about $\lambda_{\mathrm{L}}$. In the event that the $\lambda_{\mathrm{L}}$ is between 400 and $700 \mathrm{~nm}$, the $C\left(\lambda_{\mathrm{L}}\right)$ is determined by Eq. 5 [77]:

$C\left(\lambda_{L}\right) \approx 0.33 \times \lambda_{L}-12.6$

On the basis of Eqs. 4 and 5, the value of $L_{\mathrm{a}}$ decreases along with increase in $I_{\mathrm{D}} / I_{\mathrm{G}}$. It means that the dimension of graphite crystallite changes thinner and the graphitization degree for the activated samples is lower than that for NHCSs. At high temperature, $\mathrm{CO}_{2}$ can react with carbon locating on the edge of crystallite to form $\mathrm{CO}$, thus bringing massive micropores and vacancies on the surface of carbon spheres.

The ORR activities of the samples were investigated by measuring the cyclic voltammograms $(\mathrm{CV})$ and rotating disk electrode (RDE) voltammograms in $0.1 \mathrm{M} \mathrm{O}_{2}$-saturated $\mathrm{KOH}$ solution using a conventional three-electrode system. As shown in Fig. S2, the CV curves show that the cathodic peak of CANHCS-950 is more positive than those for other samples. The parameters of peak positions are listed in Fig. S2b. The ORR peaks at $-0.31,-0.29$, and $-0.27 \mathrm{~V}$ (vs. SCE) could be found for CANHCS-800, CANHCS-900 and CANHCS-950, respectively. For comparison, un-activated NHCSs was also measured and its ORR peak position is $-0.39 \mathrm{~V}$ (vs. SCE). Figure 8 a shows that the $\mathrm{CV}$ curve exhibits a pronounced peak in $\mathrm{O}_{2}$-saturated electrolyte at $-0.27 \mathrm{~V}$ (vs. SCE) while no cathodic peak is observed in $\mathrm{N}_{2}$-saturated $0.1 \mathrm{M} \mathrm{KOH}$ solution. It implies that CANHCS-950 catalyst possesses the real ORR activity.

Further measurements using the RDE were carried out by linear sweep voltammetry (LSV) in $\mathrm{O}_{2}$-saturated $0.1 \mathrm{M}$ $\mathrm{KOH}$ at a rotating speed of 400-2025 rpm (sweep rate: $10 \mathrm{mV} \mathrm{s}^{-1}$ ). The results of LSV for CANHCS-950, CANHCS-800 and CANHCS-900 are shown in Fig. 8b and Fig. S3a, b, respectively. The current densities of the LSV curves steadily increased with the increase in the rotating speed, implying mass transport emerges on the electrode surface. The kinetic parameters could be analyzed with the following Koutecky-Levich (K-L) Eqs.:

$\frac{1}{J}=\frac{1}{J_{\mathrm{k}}}+\frac{1}{B \omega^{1 / 2}}$
$\mathrm{~B}=0.2 \mathrm{nFC}_{\mathrm{O}_{2}} \mathrm{D}_{\mathrm{O}_{2}}^{2 / 3} v^{-1 / 6}$ 

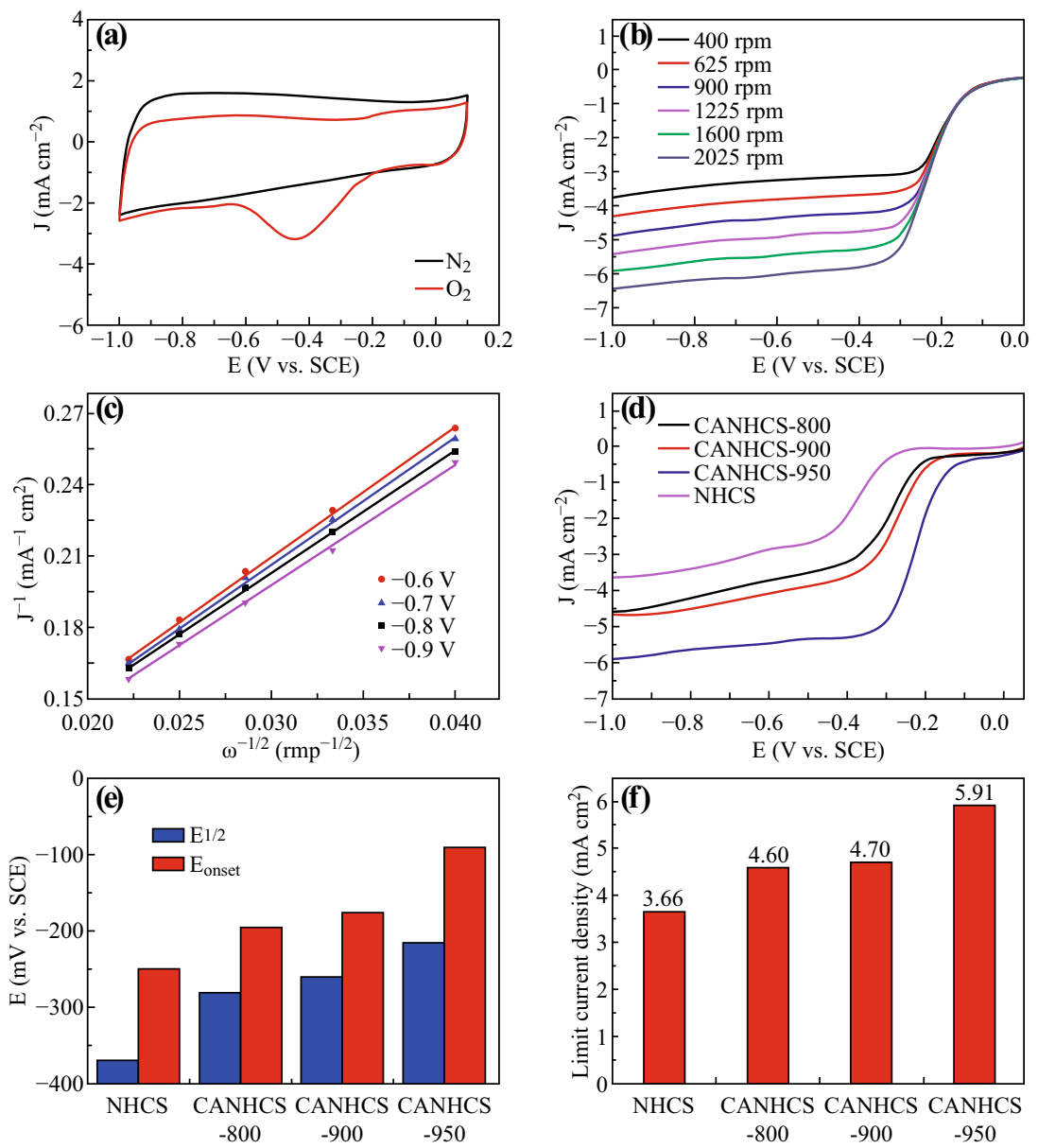

Fig. 8 a Cyclic voltammograms (CVs) of CANHCS-950 in $\mathrm{N}_{2}$ and $\mathrm{O}_{2}$-saturated $0.1 \mathrm{M} \mathrm{KOH}$ electrolyte at a scan rate of $50 \mathrm{mV} \mathrm{s}{ }^{-1}$. b Linear sweep voltammetry (LSV) curves of CANHCS-950 in $\mathrm{O}_{2}$-saturated $0.1 \mathrm{M} \mathrm{KOH}$ electrolyte at different rotation rates from 400 to $2025 \mathrm{rpm}$. $\mathbf{c}$ KL plots $\left(\mathrm{i}^{-1}\right.$ vs. $\left.\omega^{-1 / 2}\right)$ for CANHCS-950 calculated from LSV at diffident electrode potentials. d LSV curves of CANHCS-800, CANHCS-900, CANHCS-950 and NHCSs in $\mathrm{O}_{2}$-saturated $0.1 \mathrm{M} \mathrm{KOH}$ solution at a scan rate of $10 \mathrm{mv} \mathrm{s}^{-1}$ and $1600 \mathrm{rpm}$. e The onset potential $\left(E_{\text {onset }}\right)$ and the half-wave $\left(E_{1 / 2}\right)$ of CANHCS-800, CANHCS-900, CANHCS-950 and NHCSs in $\mathrm{O}_{2}$-saturated $0.1 \mathrm{M} \mathrm{KOH}$ solution at a scan rate of $10 \mathrm{mV} \mathrm{s}^{-1}$ and $1600 \mathrm{rpm}$. f Limiting current density of CANHCSs and NHCSs in $\mathrm{O}_{2}$-saturated $0.1 \mathrm{M} \mathrm{KOH}$ at a scan rate of $10 \mathrm{mV} \mathrm{s}{ }^{-1}$ and $1600 \mathrm{rpm}$

where $J$ is the measured current density, $J_{\mathrm{k}}$ is the kinetic limiting current density, $\omega$ is the electrode rotating rate, $n$ is the electron transfer number, $\mathrm{F}$ is the Faraday constant $\left(\mathrm{F}=96,485 \mathrm{C} \mathrm{mol}^{-1}\right), \mathrm{C}_{\mathrm{O} 2}$ is the bulk concentration of $\mathrm{O}_{2}$ for $0.1 \mathrm{M} \mathrm{KOH}\left(\mathrm{C}_{\mathrm{O} 2}=1.2 \times 10^{-6} \mathrm{~mol} \mathrm{~cm}^{-3}\right), D_{\mathrm{O} 2}$ is the diffusion coefficient of $\mathrm{O}_{2}$ for $0.1 \mathrm{M} \mathrm{KOH}$ $\left(\mathrm{D}_{\mathrm{O} 2}=1.9 \times 10^{-5} \mathrm{~cm}^{2} \mathrm{~s}^{-1}\right)$ and $v$ is the kinetic viscosity $\left(v=0.01 \mathrm{~cm}^{2} \mathrm{~s}^{-1}\right)$.

The K-L plots $\left(j^{-1}\right.$ vs. $\left.\omega^{-1 / 2}\right)$ are shown in Fig. $8 \mathrm{c}$, which is drawn with the values of currents at different voltage ranging from -0.6 to $-0.9 \mathrm{~V}$ (vs. SCE) and various rotation speeds. It can be seen that the dates exhibit great linearity, running parallel with each other. In order to compare the electrocatalytic activities of the samples, the LSV measurements in $\mathrm{O}_{2}$-saturated $0.1 \mathrm{M} \mathrm{KOH}$ at a rotating speed of $1600 \mathrm{rpm}$ for CANHCSs and NHCSs are listed in Fig. 8d. All CANHCSs possess more positive onset $\left(E_{\text {onset }}\right)$ and half-wave $\left(E_{1 / 2}\right)$ potential, and larger limiting current density than NHCSs (Fig. 8d-f), implying $\mathrm{CO}_{2}$ activation has a significant positive effect on the ORR activity in spite of the evident $\mathrm{N}$ loss, possibly due to enhanced specific surface area and hierarchical microstructure. It has been suggested that the large surface area could play more important role in improving the ORR activity by increasing the mass transport. Among three CANHCSs, CANHCS-950 shows the best ORR activity, reflected by its most positive $E_{\text {onset }}(-89 \mathrm{mV}$ vs. SCE) and $E_{1 / 2}$ and largest limiting current density $\left(5.91 \mathrm{~mA} \mathrm{~cm}^{-2}\right)$. This current density is much superior to those previously reported for various $\mathrm{N}$-doped carbons materials including $\mathrm{N}$-graphene [14], N-carbon spheres [77] and N-CNT/G $[52,78]$. The electrochemical ORR performances of various $\mathrm{N}$-doped carbon shells are listed in Table S1 for comparison. Relative to NHCSs and other CANHCSs, the improvement of CANHCS-950 on the ORR activity was 

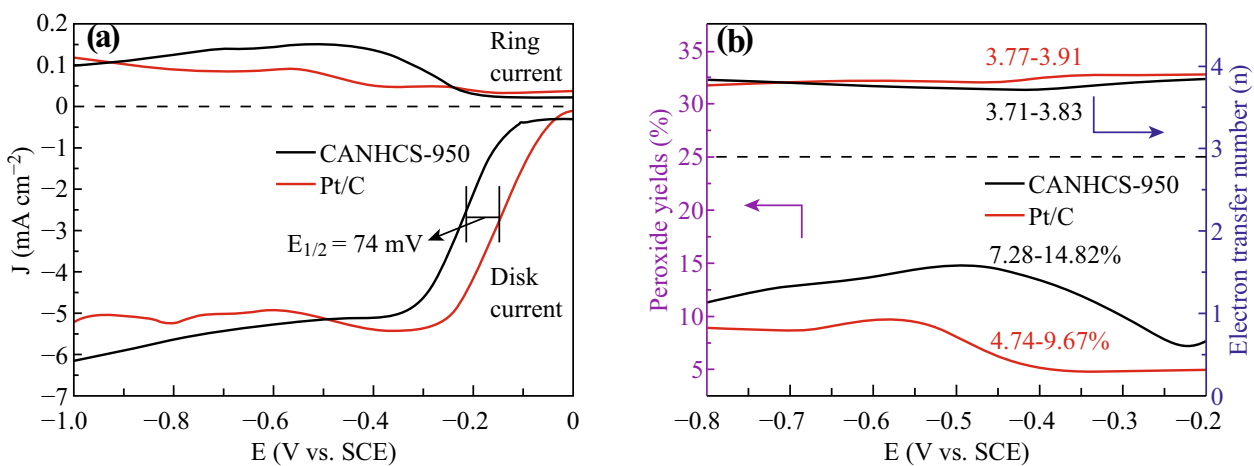

Fig. 9 a Rotating ring-disk electrode (RRDE) voltammograms for CANHCS-950 and Pt/C in $\mathrm{O}_{2}$-saturated $0.1 \mathrm{M} \mathrm{KOH}$ electrolyte at a rotation rate of $1600 \mathrm{rpm}$ with a ring potential at $0.2 \mathrm{~V}$ (vs. SCE) and $\mathbf{b}$ number of electrons transferred and peroxide yields of CANHCS-950 and Pt/C in $\mathrm{O}_{2}$-saturated $0.1 \mathrm{M} \mathrm{KOH}$ electrolyte
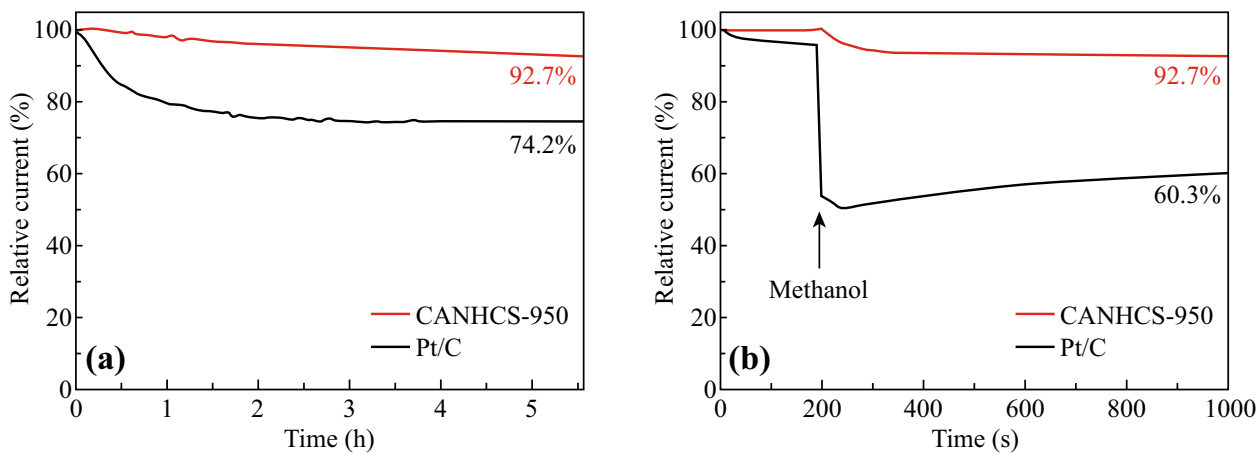

Fig. 10 a Current-time (i-t) chronoamperometric responses for CANHCS-950 and 20\% Pt/C in $\mathrm{O}_{2}$-saturated $0.1 \mathrm{M} \mathrm{KOH}$ electrolyte at $-0.6 \mathrm{~V}$ (vs. SCE) for the ORR at a rotating speed of $1600 \mathrm{rpm}$ and $\mathbf{b}$ comparison of chronoamperometric responses over $1000 \mathrm{~s}$ at a constant rotation speed of $1600 \mathrm{rpm}$ for CANHCS-950 and Pt/C in $\mathrm{O}_{2}$-saturated $0.1 \mathrm{M} \mathrm{KOH}$ electrolyte with $3 \mathrm{M}$ methanol added at $200 \mathrm{~s}$

ascribed mainly to its largest surface area and highest relative contents of pyridinic and graphitic $\mathrm{N}$ groups, which favorably promote the fast transport/diffusion of reactants, ions and electrons to exposed active sites.

In order to further discuss the electrochemical performance and the detailed investigation of the mass-transfer kinetics of CANHCS-950, a rotating ring-disk electrode (RRDE) measurement in $\mathrm{O}_{2}$-saturated $0.1 \mathrm{M} \mathrm{KOH}$ electrolytes at a rotation rate of $1600 \mathrm{rpm}$ was tested. For comparison, $20 \mathrm{wt} \% \mathrm{Pt} / \mathrm{C}$ was also tested. As shown in Fig. 9a, the gap of $E_{1 / 2}$ between CANHCS-950 and Pt/C is about $74 \mathrm{mV}$, evidently smaller than those reported for various $\mathrm{N}$-doped carbons including NCNTs [78] and Ncarbon nanocages [79]. The electron transfer number $(n)$ and peroxide yields are calculated from the RRDE data over the potential range from -0.8 to $-0.3 \mathrm{~V}$ (vs. SCE) according to Eqs. 3 and 4. Figure $9 \mathrm{~b}$ presents that the electron transfer number $(n)$ of CANHCS-950 varies in the range of 3.71-3.84, very close to that for $\mathrm{Pt} / \mathrm{C}$. It implies that the catalytic ORR process of CANHCS-950 is a $4 \mathrm{e}^{-}$dominant reaction pathway. Note that four-electron process is very important for ORR in fuel cells, because peroxides can poison the cell. Indeed, the peroxide yields for the
ORR by CANHCS-950 was calculated to be $7.28 \%$ $14.82 \%$ while the values of $\mathrm{Pt} / \mathrm{C}$ range from $7.47 \%$ to $9.67 \%$, implying a highly desirable ORR process with low yield of peroxide for CANHCS-950 to obtain maximum energy capacity. Thus, CANHCS-950 with unique hierarchical structures and large surface area could be regarded as an excellent candidate as metal-free electrocatalysts toward the ORR.

Stability is of great importance for catalysts in practical applications in fuel cell technology. The stability was tested by the chronoamperometric measurements at $-0.6 \mathrm{~V}$ (vs. SCE) in $\mathrm{O}_{2}$-saturated $0.1 \mathrm{M} \mathrm{KOH}$ electrolyte at a rotating speed of $1600 \mathrm{rpm}$. $\mathrm{Pt} / \mathrm{C}$ was also measured as a control sample to check whether CANHCS-950 has better stability under the same environment. As shown in Fig. $10 \mathrm{a}$, after $5.5 \mathrm{~h}$ of continuous operation, there is an apparent decrease in the current density for $\mathrm{Pt} / \mathrm{C}$ electrode. The current density retention rate of $\mathrm{Pt} / \mathrm{C}$ electrode is only about $74.2 \%$ while the CANHCS- 950 catalyst still retains $92.7 \%$ of the initial current density. Namely, the CANHCS-950 catalyst has the better stability for the ORR than $\mathrm{Pt} / \mathrm{C}$. The methanol poisoning effect of catalyst is another issue that needs to be addressed in practical 
applications in fuel cell technology in direct methanol fuel cells (DMFC). To analyze this issue, samples were measured by chronoamperometric measurements at $-0.6 \mathrm{~V}$ (vs. SCE) in $\mathrm{O}_{2}$-saturated $0.1 \mathrm{M} \mathrm{KOH}$ electrolyte at a rotating speed of $1600 \mathrm{rpm}$ for $1000 \mathrm{~s}$ while $3 \mathrm{M}$ methanol was added at $200 \mathrm{~s}$. As shown in Fig. 10b, after the injection of methanol, the $\mathrm{Pt} / \mathrm{C}$ electrode (black curve) decreases instantaneously for the voltammetric current and the current maintains about $60.3 \%$. However, there is a slight change for CANHCS-950 and the retention rate keeps at $92.7 \%$ in the same process, which is much higher than that of $\mathrm{Pt} / \mathrm{C}$. These results indicate that CANHCS-950 can not only keep excellent stability in alkaline solution but also perform insensitive to methanol.

\section{Conclusions}

In summary, a kind of novel N-doped carbon shells with hollow core and triple hierarchical micro-meso-macroporosity has been successfully prepared by the activation of $\mathrm{N}$-doped hollow carbon spheres in $\mathrm{CO}_{2}$ atmosphere at high temperature. The surface areas, total pore volumes and micropore percentages of the $\mathrm{CO}_{2}$-activated samples evidently increase with increasing activation temperature from 800 to $950{ }^{\circ} \mathrm{C}$, while the $\mathrm{N}$ contents show a contrary trend from 7.6 to 3.8 at\% determined by XPS. The CANHCS950 has a very high specific surface area of $2072 \mathrm{~m}^{2} \mathrm{~g}^{-1}$, pore volume of $1.96 \mathrm{~cm}^{3} \mathrm{~g}^{-1}$ and $\mathrm{N}$ doping of 3.8 at\%. The pyridinic and graphitic $\mathrm{N}$ groups are dominant in the activated samples, which are regarded as the active sites for the ORR. Combined with their hierarchical structures, the CANHCSs are beneficial for storing the electrolyte in macroporous core and transfer the reactants and electrolyte to the active sites in the mesopores, thus improving the ORR activity. The $\mathrm{CO}_{2}$ activation treatment evidently improves the limiting current density and decrease the ORR onset potential. Among the activated samples, CANHCS-950 showed the comparable ORR activity but superior methanol tolerance and long-term durability to $20 \mathrm{wt} \% \mathrm{Pt} / \mathrm{C}$ with a $4 \mathrm{e}^{-}$-dominant transfer pathway in alkaline media. Such N-doped carbon materials with unique hierarchical structure and large surface area are also potential in many fields, such as adsorption of heavy metal ions, $\mathrm{CO}_{2}$ capture, gas storage and supercapacitors.

Acknowledgements The authors thank the financial support from the National Key Research and Development Program of China (2016YFB0700204), NSFC (51502327, 51602332), Science and Technology Commission of Shanghai Municipality (15520720400, 15YF1413800, 14DZ2261203 and 16DZ2260603), Key Project for Young Researcher of State Key Laboratory of High Performance Ceramics and Superfine Microstructure and One Hundred Talent Plan of Chinese Academy of Sciences.
Open Access This article is distributed under the terms of the Creative Commons Attribution 4.0 International License (http://crea tivecommons.org/licenses/by/4.0/), which permits unrestricted use, distribution, and reproduction in any medium, provided you give appropriate credit to the original author(s) and the source, provide a link to the Creative Commons license, and indicate if changes were made.

\section{References}

1. S. Basu, Recent trends in fuel cell science and technology (Springer, New York, 2007)

2. R. Dillon, S. Srinivasan, A.S. Aricò, V. Antonucci, International activities in DMFC R\&D: status of technologies and potential applications. J. Power Sources 127(1), 112-126 (2004). doi:10. 1016/j.jpowsour.2003.09.032

3. H. Liu, C. Song, L. Zhang, J. Zhang, H. Wang, D.P. Wilkinson, A review of anode catalysis in the direct methanol fuel cell. J. Power Sources 155(2), 95-110 (2006). doi:10.1016/j.jpowsour. 2006.01.030

4. F.T. Wagner, B. Lakshmanan, M.F. Mathias, Electrochemistry and the future of the automobile. J. Phys. Chem. Lett. 1(14), 2204-2219 (2010). doi:10.1021/jz100553m

5. W. Yu, M.D. Porosoff, J.G. Chen, Review of Pt-based bimetallic catalysis: from model surfaces to supported catalysts. Chem. Rev. 112(11), 5780-5817 (2012). doi:10.1021/cr300096b

6. C. Zhu, H. Li, S. Fu, D. Du, Y. Lin, Highly efficient nonprecious metal catalysts towards oxygen reduction reaction based on threedimensional porous carbon nanostructures. Chem. Soc. Rev. 45(3), 517-531 (2016). doi:10.1039/C5CS00670H

7. B. Wang, Recent development of non-platinum catalysts for oxygen reduction reaction. J. Power Sources 152(1), 1-15 (2005). doi:10.1016/j.jpowsour.2005.05.098

8. L. Dai, Y. Xue, L. Qu, H.-J. Choi, J.-B. Baek, Metal-free catalysts for oxygen reduction reaction. Chem. Rev. 115(11), 4823-4892 (2015). doi:10.1021/cr5003563

9. X. Li, Y. Chen, X.L. Chi, Y.C. Xu, Q. Yang, H.Y. Zhang, J.L. Zhang, D.R. Xiao, Three octamolybdate-templated inorganicorganic hybrid frameworks based on dinuclear/tetranuclear metal-tetrazole clusters. Inorg. Chim. Acta 437, 159-166 (2015). doi:10.1016/j.ica.2015.08.021

10. Y. Nie, L. Li, Z. Wei, Recent advancements in Pt and Pt-free catalysts for oxygen reduction reaction. Chem. Soc. Rev. 44(8), 2168-2201 (2015). doi:10.1039/C4CS00484A

11. L. Wang, M. Yao, X. Hu, G. Hu, J. Lu, M. Luo, M. Fan, Aminemodified ordered mesoporous silica: the effect of pore size on $\mathrm{CO}_{2}$ capture performance. Appl. Surf. Sci. 324, 286-292 (2015). doi:10.1016/j.apsusc.2014.10.135

12. C. Shang, M. Li, Z. Wang, S. Wu, Z. Lu, Electrospun nitrogendoped carbon nanofibers encapsulating cobalt nanoparticles as efficient oxygen reduction reaction catalysts. Chemelectrochem 3(9), 1437-1445 (2016). doi:10.1002/celc.201600275

13. Y. Liang, Y. Li, H. Wang, J. Zhou, J. Wang, T. Regier, H. Dai, $\mathrm{Co}_{3} \mathrm{O}_{4}$ nanocrystals on graphene as a synergistic catalyst for oxygen reduction reaction. Nat. Mater. 10(10), 780-786 (2011). doi:10.1038/nmat3087

14. L. Qu, Y. Liu, J.B. Baek, L. Dai, Nitrogen-doped graphene as efficient metal-free electrocatalyst for oxygen reduction in fuel cells. ACS Nano 4(3), 1321-1326 (2010). doi:10.1021/nn901850u

15. R. Lv, T. Cui, M.S. Jun, Q. Zhang, A. Cao et al., Open-ended, $\mathrm{N}$-doped carbon nanotube-graphene hybrid nanostructures as high-performance catalyst support. Adv. Funct. Mater. 21(5), 999-1006 (2015). doi:10.1002/adfm.201001602 
16. Z. Wang, R. Jia, J. Zheng, J. Zhao, L. Li, J. Song, Z. Zhu, Nitrogen-promoted self-assembly of N-doped carbon nanotubes and their intrinsic catalysis for oxygen reduction in fuel cells. ACS Nano 5(3), 1677-1684 (2011). doi:10.1021/nn1030127

17. J. Sanetuntikul, T. Hang, S. Shanmugam, Hollow nitrogen-doped carbon spheres as efficient and durable electrocatalysts for oxygen reduction. Chem. Commun. 50(67), 9473-9476 (2014). doi:10.1039/C4CC03437F

18. Y. Lu, M. Liu, H. Nie, C. Gu, M. Liu, Z. Yang, K. Yang, X.A. Chen, S. Huang, Direct fabrication of metal-free hollow graphene balls with a self-supporting structure as efficient cathode catalysts of fuel cell. J. Nanopart. Res. 18(6), 1-9 (2016). doi:10.1007/ s11051-016-3457-3

19. Z. Wu, R. Liu, J. Wang, J. Zhu, W. Xiao, C. Xuan, W. Lei, D. Wang, Nitrogen and sulfur co-doping of 3D hollow-structured carbon spheres as an efficient and stable metal free catalyst for the oxygen reduction reaction. Nanoscale 8(45), 19086-19092 (2016). doi:10.1039/C6NR06817K

20. Y. Xia, A. Zhuxian Yang, R. Mokaya, Mesostructured hollow spheres of graphitic $\mathrm{N}$-doped carbon nanocast from spherical mesoporous silica. J. Phys. Chem. B 108(50), 19293-19298 (2009). doi:10.1021/jp046142n

21. S.Y. Lim, W. Shen, Z. Gao, Carbon quantum dots and their applications. Chem. Soc. Rev. 44(1), 362-381 (2015). doi:10. 1039/C4CS00269E

22. G. Lota, B. Grzyb, H. Machnikowska, J. Machnikowski, E. Frackowiak, Effect of nitrogen in carbon electrode on the supercapacitor performance. Chem. Phys. Lett. 404(1), 53-58 (2005). doi:10.1016/j.cplett.2005.01.074

23. W. Li, D. Chen, Z. Li, Y. Shi, Y. Wan, J. Huang, J. Yang, D. Zhao, Z. Jiang, Nitrogen enriched mesoporous carbon spheres obtained by a facile method and its application for electrochemical capacitor. Electrochem. Commun. 9(4), 569-573 (2007). doi:10.1016/j.elecom.2006.10.027

24. Q. Li, R. Jiang, Y. Dou, Z. Wu, T. Huang, D. Feng, J. Yang, A. $\mathrm{Yu}, \mathrm{D}$. Zhao, Synthesis of mesoporous carbon spheres with a hierarchical pore structure for the electrochemical double-layer capacitor. Carbon 49(4), 1248-1257 (2011). doi:10.1016/j.car bon.2010.11.043

25. S.M. Mahurin, J.S. Lee, G.A. Baker, H. Luo, S. Dai, Performance of nitrile-containing anions in task-specific ionic liquids for improved $\mathrm{CO}_{2} / \mathrm{N}_{2}$ separation. J. Membr. Sci. 353(1), 177-183 (2010). doi:10.1016/j.memsci.2010.02.045

26. G.H. Wang, J. Hilgert, F.H. Richter, F. Wang, H.J. Bongard, B. Spliethoff, C. Weidenthaler, F. Schuth, Platinum-cobalt bimetallic nanoparticles in hollow carbon nanospheres for hydrogenolysis of 5-hydroxymethylfurfural. Nat. Mater. 13(3), 293-300 (2014). doi:10.1038/nmat3872

27. D. Sud, G. Mahajan, M.P. Kaur, Agricultural waste material as potential adsorbent for sequestering heavy metal ions from aqueous solutions-a review. Bioresour. Technol. 99(14), 6017-6027 (2008). doi:10.1016/j.biortech.2007.11.064

28. S. Zhu, Q. Meng, L. Wang, J. Zhang, Y. Song, H. Jin, K. Zhang, H. Sun, H. Wang, B. Yang, Highly photoluminescent carbon dots for multicolor patterning, sensors, and bioimaging. Angew. Chem. Int. Ed. 52(14), 3953-3957 (2013). doi:10.1002/anie.201300519

29. R.A. Nistor, D.M. Newns, G.J. Martyna, The role of chemistry in graphene doping for carbon-based electronics. ACS Nano 5(4), 3096-3103 (2011). doi:10.1021/nn200225f

30. D.S. Su, J. Zhang, B. Frank, A. Thomas, X. Wang, J. Paraknowitsch, R. Schlögl, Metal-free heterogeneous catalysis for sustainable chemistry. Chemsuschem 3(2), 169-180 (2010). doi: $10.1002 /$ cssc. 200900180

31. L. Zhao, R. He, K.T. Rim, T. Schiros, K.S. Kim et al., Visualizing individual nitrogen dopants in monolayer grapheme. Science 333(6045), 999-1003 (2011). doi:10.1126/science.1208759
32. K.N. Wood, R. O'Hayre, S. Pylypenko, Recent progress on nitrogen/carbon structures designed for use in energy and sustainability applications. Energy Environ. Sci. 7(4), 1212-1249 (2014). doi:10.1039/C3EE44078H

33. L. Chen, X. Cui, Y. Wang, M. Wang, R. Qiu et al., One-step synthesis of sulfur doped graphene foam for oxygen reduction reactions. Dalton Trans. 43(9), 3420-3423 (2014). doi:10.1039/ c3dt52253a

34. Y.C. Lin, C.Y. Lin, P.W. Chiu, Controllable graphene N-doping with ammonia plasma. Appl. Phys. Lett. 96(13), 133110 (2010). doi:10.1063/1.3368697

35. C. Shen, G. Huang, Y. Cheng, R. Cao, F. Ding, U. Schwingenschlögl, Y. Mei, Thinning and functionalization of few-layer graphene sheets by $\mathrm{CF}_{4}$ plasma treatment. Nanoscale Res. Lett. 7(1), 1-8 (2012). doi:10.1186/1556-276X-7-268

36. G. Tao, L. Zhang, L. Chen, X. Cui, Z. Hua, M. Wang, J. Wang, Y. Chen, J. Shi, N-doped hierarchically macro/mesoporous carbon with excellent electrocatalytic activity and durability for oxygen reduction reaction. Carbon 86, 108-117 (2015). doi:10. 1016/j.carbon.2014.12.102

37. D. Geng, Y. Chen, Y. Chen, Y. Li, R. Li, X. Sun, S. Ye, S. Knights, High oxygen-reduction activity and durability of nitrogen-doped grapheme. Energy Environ. Sci. 4(3), 760-764 (2011). doi:10.1039/c0ee00326c

38. R. Ma, X. Ren, B.Y. Xia, Y. Zhou, C. Sun, Q. Liu, J. Liu, J. Wang, Novel synthesis of $\mathrm{N}$-doped graphene as an efficient electrocatalyst towards oxygen reduction. Nano Res. 9(3), 808-819 (2016). doi:10.1007/s12274-015-0960-2

39. R. Ma, B.Y. Xia, Y. Zhou, P. Li, Y. Chen, Q. Liu, J. Wang, Ionic liquid-assisted synthesis of dual-doped graphene as efficient electrocatalysts for oxygen reduction. Carbon 102, 58-65 (2016). doi:10.1016/j.carbon.2016.02.034

40. H.J. Cui, H.M. Yu, J.F. Zheng, Z.J. Wang, Y.Y. Zhu, S.P. Jia, J. Jia, Z.P. Zhu, N-doped graphene frameworks with superhigh surface area: excellent electrocatalytic performance for oxygen reduction. Nanoscale 8(5), 2795-2803 (2016). doi:10.1039/ C5NR06319A

41. Z. Chen, D. Higgins, H. Tao, R.S. Hsu, Z. Chen, Highly active nitrogen-doped carbon nanotubes for oxygen reduction reaction in fuel cell applications. J. Phys. Chem. C 113(113), 21008-21013 (2009). doi:10.1021/jp908067v

42. W. Xiong, F. Du, Y. Liu, J. Albert Perez, M. Supp, T.S. Ramakrishnan, L. Dai, L. Jiang, 3-D carbon nanotube structures used as high performance catalyst for oxygen reduction reaction. J. Am. Chem. Soc. 132(45), 15839-15841 (2010). doi:10.1021/ ja104425h

43. K. Gong, F. Du, Z. Xia, M. Durstock, L. Dai, Nitrogen-doped carbon nanotube arrays with high electrocatalytic activity for oxygen reduction. Science 323(5915), 760-764 (2009). doi:10. 1126/science.1168049

44. Y.T. Lee, N.S. Kim, S.Y. Bae, J. Park, S.C. Yu, H. Ryu, H.J. Lee, Growth of vertically aligned nitrogen-doped carbon nanotubes: control of the nitrogen content over the temperature range 900-1100 ${ }^{\circ}$ C. J. Phys. Chem. B 107(47), 12958-12963 (2003). doi:10.1021/jp0274536

45. H. Li, H. Liu, Z. Jong, Q. Wei, D. Geng, X. Sun, H. Wang, Nitrogen-doped carbon nanotubes with high activity for oxygen reduction in alkaline media. Int. J. Hydrog Energy 36(3), 2258-2265 (2011). doi:10.1016/j.ijhydene.2010.11.025

46. Y. Chen, Q. Liu, J. Wang, Carbon dioxide activated carbon nanofibers with hierarchical micro-/mesoporosity towards electrocatalytic oxygen reduction. J. Mater. Chem. A 4(15), 5553-5560 (2016). doi:10.1039/C6TA00136J

47. P. Chen, L.K. Wang, G. Wang, M.R. Gao, J. Ge, W.J. Yuan, Y. Shen, A. Xie, S.H. Yu, Nitrogen-doped nanoporous carbon nanosheets derived from plant biomass: an efficient catalyst for 
oxygen reduction reaction. Energy Environ. Sci. 7(12), 4095-4103 (2014). doi:10.1039/C4EE02531H

48. G. Panomsuwan, N. Saito, T. Ishizaki, Electrocatalytic oxygen reduction on nitrogen-doped carbon nanoparticles derived from cyano-aromatic molecules via a solution plasma approach. Carbon 98, 411-420 (2016). doi:10.1016/j.carbon.2015.11.013

49. F. Zheng, G. Mu, Z. Zhang, Y. Shen, M. Zhao, G. Pang, Nitrogen-doped hollow macroporous carbon spheres with high electrocatalytic activity for oxygen reduction. Mater. Lett. 68(1), 453-456 (2012). doi:10.1016/j.matlet.2011.11.035

50. B. Bayatsarmadi, Y. Zheng, M. Jaroniec, S. Qiao, Soft-templating synthesis of $\mathrm{N}$-doped mesoporous carbon nanospheres for enhanced oxygen reduction reaction. Chem. Asian J. 10(7), 1546-1553 (2015). doi:10.1002/asia.201500287

51. T. Yang, J. Liu, R. Zhou, Z. Chen, H. Xu, S. Qiao, M. Monteiro, $\mathrm{N}$-doped mesoporous carbon spheres as the oxygen reduction reaction catalysts. J. Mater. Chem. A 2(42), 18139-18146 (2014). doi:10.1039/C4TA04301D

52. Y. Ma, L. Sun, W. Huang, L. Zhang, J. Zhao, Q. Fan, W. Huang, Three-dimensional nitrogen-doped carbon nanotubes/graphene structure used as a metal-free electrocatalyst for the oxygen reduction reaction. J. Phys. Chem. C 115(50), 24592-24597 (2012). doi:10.1021/jp207736h

53. S.M. Unni, R. Illathvalappil, P.K. Gangadharan, S.N. Bhange, S. Kurungot, Layer-separated distribution of nitrogen doped graphene by wrapping on carbon nitride tetrapods for enhanced oxygen reduction reaction in acid medium. Chem. Commun. 50(89), 13769-13772 (2014). doi:10.1039/C4CC06180B

54. C. Xiong, Z. Wei, B. Hu, S. Chen, L. Li, L. Guo, W. Ding, X. Liu, W. Ji, X. Wang, Nitrogen-doped carbon nanotubes as catalysts for oxygen reduction reaction. J. Power Sources 215(5), 216-220 (2012). doi:10.1016/j.jpowsour.2012.04.057

55. D. Yu, Q. Zhang, L. Dai, Highly efficient metal-free growth of nitrogen-doped single-walled carbon nanotubes on plasma-etched substrates for oxygen reduction. J. Am. Chem. Soc. 132(43), 15127-15129 (2010). doi:10.1021/ja105617z

56. G. Lalande, D. Guay, J.P. Dodelet, G. Denes, Influence of nitrogen-containing precursors on the electrocatalytic activity of heat-treated $\mathrm{Fe}(\mathrm{OH})_{2}$ on carbon black for $\mathrm{O}_{2}$ reduction. J. Electrochem. Soc. 145(7), 2411-2418 (1998). doi:10.1149/1.1838651

57. M. Xiao, J. Zhu, L. Feng, C. Liu, W. Xing, Meso/macroporous nitrogen-doped carbon architectures with iron carbide encapsulated in graphitic layers as an efficient and robust catalyst for the oxygen reduction reaction in both acidic and alkaline solutions. Adv. Mater. 27(15), 2521-2527 (2015). doi:10.1002/adma. 201500262

58. J. Wang, S. Kaskel, KOH activation of carbon-based materials for energy storage. J. Mater. Chem. 22(45), 23710-23725 (2012). doi:10.1039/c2jm34066f

59. S. Sircar, T.C. Golden, M.B. Rao, Activated carbon for gas separation and storage. Carbon 34(1), 1-12 (1996). doi:10.1016/ 0008-6223(95)00128-X

60. M.A. Elsayed, P.J. Hall, M.J. Heslop, Preparation and structure characterization of carbons prepared from resorcinol-formaldehyde resin by $\mathrm{CO}_{2}$ activation. Adsorption 13(3), 299-306 (2007). doi:10.1007/s10450-007-9065-x

61. K. Xia, Q. Gao, S. Song, C. Wu, J. Jiang, J. Hu, L. Gao, $\mathrm{CO}_{2}$ activation of ordered porous carbon CMK-1 for hydrogen storage. Int. J. Hydrog. Energy 33(1), 116-123 (2008). doi:10.1016/j. ijhydene.2007.08.019

62. A.A. Rownaghi, F. Rezaei, M. Stante, J. Hedlund, Selective dehydration of methanol to dimethyl ether on ZSM-5 nanocrystals. Appl. Catal. B Environ. 119, 56-61 (2012). doi:10.1016/j. apcatb.2012.02.017

63. W.J. Sweet, J.S. Jur, G.N. Parsons, Bi-layer $\mathrm{Al}_{2} \mathrm{O}_{3} / \mathrm{ZnO}$ atomic layer deposition for controllable conductive coatings on polypropylene nonwoven fiber mats. J. Appl. Phys. 113(19), 1415 (2013). doi:10.1063/1.4804960

64. S. Tao, Y. Wang, Y. Yu, Y. An, W. Shi, Hierarchically porous tungstophosphoric acid/silica hybrid for high performance vislight photocatalysis. J. Environ. Chem. Eng. 1(4), 719-727 (2013). doi:10.1016/j.jece.2013.07.012

65. D.W. Wang, F. Li, M. Liu, G.Q. Lu, H.M. Cheng, Mesoporeaspect-ratio dependence of ion transport in rodtype ordered mesoporous carbon. J. Phys. Chem. C 112(26), 9950-9955 (2008). doi:10.1021/jp800173z

66. K. Xia, X. Tian, S. Fei, K. You, Hierarchical porous graphenebased carbons prepared by carbon dioxide activation and their gas adsorption properties. Int. J. Hydrog. Energy 39(21), 11047-11054 (2014). doi:10.1016/j.ijhydene.2014.05.059

67. F. Liu, C. Liu, W. Kong, C. Qi, A. Zheng, S. Dai, Design and synthesis of micro-meso-macroporous polymers with versatile active sites and excellent activities in production of biofuels and fine chemicals. Green Chem. 18(24), 6536-6544 (2016). doi:10. 1039/C6GC02237E

68. H.W. Liang, X. Zhuang, S. Brüller, X. Feng, K. Müllen, Hierarchically porous carbons with optimized nitrogen doping as highly active electrocatalysts for oxygen reduction. Nat. Commun. 5(5), 4973 (2014). doi:10.1038/ncomms5973

69. Y. Zheng, Y. Jiao, L. Ge, M. Jaroniec, S.Z. Qiao, Two-step boron and nitrogen doping in graphene for enhanced synergistic catalysis. Angew. Chem. Int. Ed. 52(11), 3110-3116 (2013). doi:10. 1002/anie.201209548

70. J. Wang, Q. Liu, An efficient one-step condensation and activation strategy to synthesize porous carbons with optimal micropore sizes for highly selective $\mathrm{CO}_{2}$ adsorption. Nanoscale 6(8), 4148-4156 (2014). doi:10.1039/C3NR05825E

71. L.S. Panchakarla, A. Govindaraj, C.N. Rao, Nitrogen-and borondoped double-walled carbon nanotubes. ACS Nano 1(5), 494-500 (2007). doi:10.1021/nn700230n

72. S. Wu, Y. Zhu, Y. Huo, Y. Luo, L. Zhang et al., Bimetallic organic frameworks derived $\mathrm{CuNi}$ /carbon nanocomposites as efficient electrocatalysts for oxygen reduction reaction. Sci. China Mater. 60(7), 654-663 (2017). doi:10.1007/s40843-017-9041-0

73. L. Sun, C. Tian, Y. Fu, Y. Yang, J. Yin, L. Wang, H. Fu, Nitrogen-doped porous graphitic carbon as an excellent electrode material for advanced supercapacitors. Chem. Eur. J. 20(2), 564-574 (2014). doi:10.1002/chem.201303345

74. S.B. Yoon, G.S. Chai, S.K. Kang, J.S. Yu, K.P. Gierszal, M. Jaroniec, Graphitized pitch-based carbons with ordered nanopores synthesized by using colloidal crystals as templates. J. Am. Chem. Soc. 127(12), 4188-4189 (2005). doi:10.1021/ja0423466

75. D.S. Knight, W.B. White, Characterization of diamond films by Raman spectroscopy. J. Mater. Res. 4(2), 385-393 (1989). doi:10. 1557/JMR.1989.0385

76. M.J. Matthews, M.A. Pimenta, G. Dresselhaus, M.S. Dresselhaus, M. Endo, Origin of dispersive effects of the Raman D band in carbon materials. Phys. Rev. B 59(10), R6585-R6588 (1999). doi:10.1103/PhysRevB.59.R6585

77. J. Tang, J. Liu, C. Li, Y. Li, M.O. Tade, S. Dai, Y. Yamauchi, Synthesis of nitrogen-doped mesoporous carbon spheres with extra-large pores through assembly of diblock copolymer micelles. Angew. Chem. Int. Ed. 54(2), 588-593 (2015). doi:10. 1002/ange.201407629

78. C.V. Rao, C.R. Cabrera, Y. Ishikawa, In search of the active site in nitrogen-doped carbon nanotube electrodes for the oxygen reduction reaction. J. Phys. Chem. Lett. 1(18), 2622-2627 (2010). doi:10.1021/jz100971v

79. S. Chen, J. Bi, Y. Zhao, L. Yang, C. Zhang, Y. Ma, Q. Wu, X. Wang, Z. Hu, Nitrogen-doped carbon nanocages as efficient metal-free electrocatalysts for oxygen reduction reaction. Adv. Mater. 24(41), 5593-5597 (2012). doi:10.1002/adma.201202424 